\title{
PRODUCT DIFFERENTIATION STRATEGY AND VERTICAL INTEGRATION: AN APPLICATION TO THE DOC RIOJA WINE INDUSTRY
}

\author{
Marta FERNÁNDEZ-OLMOS ${ }^{1}$, Natalia DEJO-ORICAIN ${ }^{2}$, \\ Jorge ROSELL-MARTÍNEZ ${ }^{3}$ \\ 1, 2 Department of Business Administration, University of Zaragoza, \\ Gran Via, 2, 50005 Zaragoza, Spain \\ ${ }^{3}$ Defense University Center, University of Zaragoza, \\ Ctra Huesca s/n, 50090 Zaragoza, Spain \\ E-mails: ${ }^{1}$ maferno@unizar.es (corresponding author); \\ 2ndejo@unizar.es; 3jrosell@unizar.es \\ Received 17 April 2013; accepted 11 June 2013
}

\begin{abstract}
This study evaluates the importance of product differentiation as a determinant of vertical integration in firms. The proposed model also controls for known determinants of integration, such as transaction costs and firm-level capabilities. By identifying transaction-, firm- and strategy-level determinants, we derive testable predictions about the vertical integration decision. To test these predictions we analyze the Rioja wine industry, using a representative sample of 187 firms. Our paper concludes that reaching judicious vertical integration decisions requires a thorough analysis of some very diverse aspects, especially those related to mitigating opportunism, dealing with unforeseen contingencies and product differentiation.
\end{abstract}

Keywords: transaction cost economics, resource based view, product differentiation, vertical integration, wine industry, opportunism.

JEL classification: L22.

\section{Introduction}

The organizational field of study is largely concerned with explaining firm boundaries, and this is an issue of great strategic importance for managers (Leiblein et al. 2002; Díez-Vial 2007). Indeed, understanding why some firms produce a good or service themselves, while others outsource this to another organization, is one of the central issues in industrial organization.

Many explanations for vertical integration decisions have been offered. In the strategic management literature it is argued that a high degree of vertical integration between the links in the value chain is important for quality control and innovation (Porter 1980). However, some economists have argued that vertical integration decisions are based on 
reducing transaction costs. As asset specificity becomes significant, bilateral dependence increases and vertical integration will be relatively more efficient because of its coordination capacity (Williamson 1979). Finally, the basic assumption underlying the resource-based view is that vertical integration may be adopted by a firm to create a competitive advantage and increase the chance of being able to appropriate economic rents and protect rare, difficult to imitate and costly resources (Barney 2002).

While all these points of view have contributed to our understanding of the vertical boundaries of a firm, each approach offers managerial suggestions that on their own are incomplete. We argue that each theory could lead to sub-optimal performance if followed in isolation.

This paper tries to improve upon the prescriptions in the literature by constructing and testing a model that integrates several approaches into a single framework. In doing so, the paper extends the empirical literature on vertical integration by examining the relative economic and statistical importance of the prescriptions associated with the strategic management literature, transaction cost economics and the capability-based approach. We seek to provide a comprehensive and accurate understanding of how firms establish their vertical boundaries and resolve the trade-offs involved in the different explanations.

Many of the empirical studies on vertical integration that use as their foundation the transaction cost economics approach have found support for the theory's main hypotheses. In comparison with transaction cost economics, there are far fewer empirical papers examining the effects of a firm's capabilities on its vertical boundaries. Some recent studies of this type have suggested that vertical integration is conditioned not only by transaction costs, but also by production cost differences (Argyres 1996). Finally, in the strategic management literature most studies have focused on specific strategic issues associated with vertical integration in the value chain. These include an improved ability to differentiate the product and greater product and process quality (e.g., Kumpe, Bolwijn 1988). It is therefore remarkable that the empirical literature throws so little light on how product differentiation motivates firms to integrate vertically. This paper helps to fill this gap by analysing the role that product differentiation strategies play, over and above the other factors, in determining vertical integration.

In other words, the aim of this paper is to evaluate the extent to which a firm's product differentiation strategy determines its vertical integration, accounting for other well-known determinants from the transaction cost economics and resource-based approaches. We test our hypotheses on the Rioja wine industry. This industry offers some benefits as a research study. Its main input (grapes) is a non-standardized supply; it is an important and internationally respected wine producing region; vertical product differentiation may be objectively determined; it offers enough variability among firms; and, finally, it is a bounded industry so a highly representative sample is achievable. The paper is structured as follows. Section 1 discusses the theoretical framework for understanding vertical integration decisions. Section 2 describes the data and methodology used to test the hypotheses. A discussion of the results is set out in section 3. Finally, the last section presents the main conclusions of the study. 


\section{Theoretical framework}

\subsection{Vertical integration and transaction costs}

Transaction cost theory maintains that there are hazards associated with conducting certain types of transactions in the market, and that these types of transactions will therefore be performed more efficiently within a firm (Coase 1937). Williamson (1985) and Klein et al. (1978) suggest that the main contractual hazard is hold-up, whereby the party whose investments in the transaction can be freely transferred elsewhere expropriates quasi-rents from the party investing in transaction-specific assets that are non-valuable in alternative uses. Transaction cost theory predicts that internalization, or hierarchy, may reduce the potential for such opportunistic behaviour by reducing the incentive for contracting parties to engage in hold-up. This is in part through creating an environment in which "adaptive, sequential decision-making" supported by the threat of fiat may occur, and where the courts forbear from intervening (Williamson 1975, 1991). Internalization, however, implies added bureaucratic costs and reduced incentives (Williamson 1985). Therefore, we can advance that:

H1: The greater the potential transaction specificity of assets, the greater the likelihood of vertical integration.

An earlier model developed by Williamson (1975) proposed three other important factors that also drive integration decisions, namely transaction frequency, uncertainty, and small-numbers bargaining.

According to Williamson (1975), transactions characterized by small-numbers bargaining are also hazardous because such transactions are more subject to haggling, delay, and other strategic behaviour by the parties when contractual disturbances arise. Evidence to support the hypothesis that vertical integration increases as concentration in the supplier market increases, even controlling for asset specificity, has been obtained in various prior studies (e.g., Levy 1985; Caves, Bradburd 1988; Leiblein et al. 2002). In terms of food industries, Frank and Henderson (1992) and Bhuyan (2005) find supporting evidence for vertical integration in the U.S. food manufacturing industries. The small-numbers bargaining hypothesis is therefore as follows:

H2: The smaller the number of suppliers in the upstream market, the greater the likelihood of vertical integration by downstream producers.

A basic assumption in transaction cost theory is that all transactions are conducted with a certain degree of imperfect information, which can affect exchanges.

Environmental uncertainty exists when the circumstances surrounding the exchange cannot be specified in advance. This makes writing contracts more complicated, since the parties will have to devote a lot of time to trying to identify the various contingencies that may arise. Nevertheless, although transactions will be completed less smoothly than in other, more certain environments, the use of the market is still advantageous. Hence, unpredictability per se does not favour vertical integration, and only does so in conjunction with asset specificity (Williamson 1979, 1985). This interaction effect between unpredictability and asset specificity has been identified by Anderson (1985), 
Coles and Hesterly (1998), Leiblein and Miller (2003) and Díez-Vial (2007). The following hypothesis can therefore be proposed:

H3: In the presence of asset specificity, the greater the environmental uncertainty, the greater the likelihood of using vertical integration.

A second form of uncertainty, linked to the difficulty of evaluating performance, is identified in Williamson's later works (1981) as "internal" uncertainty. Contracting parties should be able to evaluate the service or product being exchanged. If performance cannot be easily assessed, the market will fail because there is no knowledge on what to reward and how to reward (Williamson, 1981). Based on this reasoning, we hypothesize that increased internal uncertainty for a transaction will lead to the increased use of vertical integration. This general hypothesis has gained some degree of support in the empirical research (e.g. Anderson, Schmittlein 1984; Anderson 1985; Gatignon, Anderson 1988; John, Weitz 1988).

H4: The greater the internal uncertainty, the greater the likelihood of using vertical integration.

We use the term frequency to refer to the regularity of the transaction. For the purposes of this particular study, however, we do not measure the effects of frequency because all transactions that were examined occurred with the same frequency.

Besides specificity and uncertainty, Williamson (1981) argued that other factors are also bound to have an impact in a given setting. In particular, Williamson (1974) points to diseconomies of scale as a factor limiting the degree of vertical integration. This is because internalization comes at the cost of additional bureaucracy and weaker incentives (Williamson 1985). Empirical evidence has been provided to support this idea (Martin 1986; Scherer, Ross 1990; Russo 1992; Bhuyan 2005). All of this leads us to consider the following hypothesis:

H5: The larger the firm, the less the likelihood of using vertical integration.

\subsection{Vertical integration and firm capabilities}

The resource- and capability-based view of the firm emphasizes the management of a firm's resource and capability portfolio as a key determinant in the configuration and boundaries of a firm. This view has provided additional theoretical and empirical explanations for vertical integration decisions. Within this framework, vertical integration decisions may be driven by a firm's attempts to leverage and protect idiosyncratic capabilities. Argyres (1996) tested this theory using several examples from manufacturing firms. The findings support the proposition that firms outsource when suppliers possess superior capabilities, except when higher costs are acceptable in the short-term while capabilities are being developed in-house. Likewise, Poppo and Zenger (1998) empirically link the presence of skill sets to vertical integration decisions. Barney (1999) suggests that integration decisions are jointly determined by the expected cost of opportunism associated with accessing a factor through the market-place and the expected cost of creating that factor inside the firm. Hence, a firm with innovation and marketing skills, which are valuable and difficult-to-imitate due to their intangible nature, will be more likely to integrate than its competitors. Therefore, we hypothesize that: 
H6: Marketing-intensive firms are more likely to choose integration for their transactions.

H7: Innovation-intensive firms are more likely to choose integration for their transactions.

With the constant pressure to meet consumer demands and be competitive, firms must continually acquire, develop and upgrade their resources and capabilities (Wernerfelt, Montgomery 1988; Robins, Wiersema 1995; Argyres 1996). Hence, identifying the source of strategic resources and capabilities (those that establish and enhance a firm's sustainable competitive advantage) represents one of the most complex challenges facing a firm. Although some authors ascribe capabilities to luck (Barney 1986), resources and capabilities are traditionally considered as the product of a history of specific routines developed experientially in the firm. They are said to develop cumulatively, as firms learn to perform routines over time (Nelson, Winter 1982). As a result, some authors hypothesize that a firm with production experience will be more likely to integrate because this provides learning opportunities that enhance its production capabilities (Leiblein, Miller 2003).

H8: The greater the experience of the firm, the greater the likelihood of vertical integration.

\subsection{Vertical integration and product differentiation strategy}

Strategic management literature contains many studies that focus on a variety of vertical integration benefits that influence product differentiation. A common argument is that increased control over adjacent phases may enhance a firm's ability to differentiate its product (Porter 1980). We can distinguish between specific strategic issues associated with integrating forward and backward in the value chain. Whereas backward integration may allow a firm to obtain specialized inputs to improve or at least differentiate its final product, forward integration gives a firm better or more timely access to market information, allowing for more rapid or specified adjustments of the product to meet consumer demands (Porter 1980). Therefore, this strand of the literature argues that firms seeking product differentiation are motivated to vertically integrate because this allows for product quality improvements through control of the input quality and output distribution and service (Hill, Jones 2008). Based on this reasoning, we establish the following hypothesis:

H9: The more differentiated a firm's product, the greater the likelihood of vertical integration.

\section{Methodology}

\subsection{Sampling and data collection}

In this study, our aim is to examine the motives for vertical integration in the Rioja Designation of Origin wine industry. The data were collected through the use of a structured survey. The population from which the sample is drawn consists of wineries 
that fulfil the following requisites ${ }^{1}$ : (1) they belong to the Rioja Designation of Origin, (2) they are wine producers, (3) they are required to file accounting information with the authorities, and (4) they are not cooperatives. The survey resulted in 187 valid participants, 88.2 percent of the population. In order to limit the influence of external shocks, the study period is the last 3-year period. Most of the wineries in the sample $(54.5 \%)$ are partially integrated, while $15 \%$ are totally vertically integrated and $30.5 \%$ are vertically disintegrated.

\subsection{Operationalization of variables}

A total of eleven determinant variables were operationalized. These measures were grouped into the three sets: transactional attributes, firm-level capabilities and product differentiation strategy. The following is a description of each of the eleven measures, by group:

\section{(i) Measuring transaction attributes}

For this set of determinant variables, we operationalized measures of specific assets, small numbers, uncertainty and size.

We use seven-point scales, bounded by "strongly disagree" and "strongly agree", to measure some transaction cost elements, specificity and uncertainty. The constructs were operationalized with a mix of original and adapted items used in previous survey-based transaction cost studies.

Specific assets (H1). Asset specificity can take several forms. For the purpose of this study, we focus on physical asset specificity and dedicated assets.

Two complementary measures of physical asset specificity were developed. The first measure is the degree of downstream physical asset specificity, which measures the total fixed investment by the producer. A second measure, the degree of upstream physical asset specificity, asked about the fixed investments made by the primary producer.

Dedicated asset specificity was operationalized as the excess capacity that a primary producer has to support in case the grapes grown for a particular winery are rejected by it.

Small numbers (H2). We used one item that asked producers how many growers on average would be willing to enter into contracts with them. Following Fowler (1995), instead of asking the exact number of suppliers, seven choices were provided on a scale where higher scores indicate a smaller number of available suppliers.

Environmental uncertainty (H3). Following Williamson (1975), we highlight one type of environmental uncertainty, that of environmental unpredictability. The scaling of this concept is based on one item that indicates respondents' perceptions of the environmental volatility.

\footnotetext{
${ }^{1}$ The population was drawn from the 2007 list provided by the Regulatory Council of the Rioja Designation of Origin.
} 
As we mentioned earlier, the presumption of market superiority is undisturbed unless assets are specific to a non-trivial degree (Williamson 1979). Following Coles and Hesterly (1998), this condition was operationalized by means of an interaction between a dummy variable $(\lambda)$ and environmental uncertainty. This dummy variable takes a value of 1 if the value of all specificity items is above 1 (the minimal value on the scale), and 0 for values of 1 .

Internal uncertainty (H4). One question, adapted from Anderson and Schmittlein (1984), addressed the perceived difficulty of measuring the results of individual growers equitably.

Size (H5). We used the logarithm of the storage capacity of the winery because the variables based on assets owned by the winery are directly dependent on the decision to integrate production activities (Leiblein, Miller 2003).

\section{(ii) Measuring firm-level capabilities}

Marketing intensity (H6). We use the ratio of advertising and promotional expenditures to sales as a proxy for marketing communication intensity.

Innovation intensity (H7). An appropriate indicator of a firm's innovation capability is the intensity of its spending on research and development (measured by the ratio of research and development expenditures to sales).

Experience (H8). We measure experience as the number of years of experience in winemaking.

\section{(iii) Measuring product differentiation}

Product differentiation (H9). In order to examine the effect of vertical product differentiation we measure the weight $s_{i}$ of every product category $\left(i^{t h}\right)$ in total firm sales. According to the classification provided by the DOC Rioja Regulatory Board, the corresponding categories, ordered by value added, are as follows: Garantía de Origen, Crianza, Reserva and Gran Reserva. A firm with a high share in the latter two should be considered a firm focused on high willingness-to-pay products. A firm with high shares in garantía de origen and crianza should be considered a firm focused on low value added products.

Following this classification, we calculate the quadratic ${ }^{2}$ shares of each type of wine in each firm's total sales. The variables are referenced by appending a subscript (the name of the category) behind the name "Share".

In order to measure the dependent variable, the degree of vertical integration between two stages in the production process, respondents (wine-making producers) were directly asked to indicate the percentage of inputs (grapes) used that are internally provided. A Tobit technique was used to statistically relate the survey items to the vertical integration decision.

\footnotetext{
2 This corresponds to the disaggregated index of diversification suggested by McVey (1972). It has the form $\sum s_{i}^{2}$, where $s_{i}$ is the share of the $i^{\text {th }}$ product in total sales.
} 


\section{Results and discussion}

Although there are significant correlations ${ }^{3}$ between some pairs of variables, on the whole there is no indication of any major multicollinearity problems. Further evidence of a lack of multicollinearity is provided by the stability of the coefficients in the estimations across the models.

Table 1 gives the coefficient estimates and goodness of fit measures for the nine hypothesized determinants of vertical integration using the Tobit estimation. An important issue with models is their stability. To test for this, different models were estimated using various specifications (Models I to IV). Given the stability of our results across specifications, our discussion focuses solely on model IV:

Table 1. Estimates using Tobit for censored data at two extremes $(0,100)$

\begin{tabular}{|c|c|c|c|c|}
\hline \multirow{2}{*}{ Variables } & \multicolumn{4}{|c|}{ Estimated parameters coefficients (standard errors) } \\
\hline & Model I & Model II & Model III & Model IV \\
\hline $\begin{array}{l}\text { Downstream physical } \\
\text { specific assets }\end{array}$ & $2.592(2.177)$ & $3.266(2.079)$ & $3.342(1.886)$ & $2.744(1.805)$ \\
\hline $\begin{array}{l}\text { Upstream physical specific } \\
\text { assets }\end{array}$ & $7.194(2.360) * *$ & $6.741(2.247)^{* *}$ & $5.259(2.039)^{*}$ & $4.620(1.946)^{*}$ \\
\hline Dedicated specific assets & $5.869(2.137) * *$ & $5.315(2.036)^{*}$ & $5.533(1.883)^{* *}$ & $6.234(1.857)^{* *}$ \\
\hline Small numbers & $4.123(2.373)$ & $3.033(2.278)$ & $1.714) 2.084)$ & $1.635(2.024)$ \\
\hline $\begin{array}{l}\lambda * \text { Environmental } \\
\text { uncertainty }\end{array}$ & $11.787(2.579)^{* *}$ & $10.296(2.452)^{* *}$ & $8.165(2.252)^{* *}$ & $8.975(2.168)^{* *}$ \\
\hline Internal uncertainty & $4.736(2.395)$ & $4.530(2.292)$ & $3.752(2.098)$ & $2.305(2.079)$ \\
\hline Size & & $-11.351(2.888)^{* *}$ & $-12.921(2.671)^{* *}$ & $-11.426(2.731)^{* *}$ \\
\hline $\begin{array}{l}\text { Marketing communication } \\
\text { intensity }\end{array}$ & & & $2.124(0.941)^{*}$ & $1.931(0.985)$ \\
\hline Innovation intensity & & & $2.875(1.589)$ & $2.008(1.550)$ \\
\hline Experience & & & $0.422(0.100)^{* *}$ & $0.370(0.097)^{* *}$ \\
\hline Share ${ }_{\text {GARANTIA DE ORIGEN }}^{2}$ & & & & $0.002(0.002)$ \\
\hline Share ${ }_{\text {CRIANZA }}^{2}$ & & & & $0.000(0.002)$ \\
\hline Share ${ }_{\text {RESERVA }}^{2}$ & & & & $0.004(0.002)^{*}$ \\
\hline Share $_{\text {GRANRESERVA }}^{2}$ & & & & $0.010(0.004)^{*}$ \\
\hline $\begin{array}{l}\text { Cragg-Uhler (Nagelkerke) } \\
\mathrm{R}^{2}\end{array}$ & 0.374 & 0.423 & 0.508 & 0.546 \\
\hline Log likelihood & -610.994 & -603.294 & -588.435 & -581.029 \\
\hline Chi-square statistic & 0.0000 & 0.0000 & 0.0000 & 0.0000 \\
\hline
\end{tabular}

Notes: ${ }^{\psi} N=187$ for all models; Levels of significance: ${ }^{*} \mathrm{p}<0.05 ;{ }^{*} \mathrm{p}<0.01$; Parameter estimates for constants are omitted; $\lambda$ represents the non-trivial degree of specificity.

\footnotetext{
${ }^{3}$ Table of correlations is available upon request.
} 
Our results provide strong support for some of the hypotheses deriving from transaction-cost theory. According to hypothesis 1, the transaction specificity of assets leads to integration. This has been largely corroborated by the parameters for the upstream specificity of physical assets and dedicated assets. Conversely, the downstream specificity of physical assets is almost insignificant. Contrary to our expectations, the results fail to support the existence of a significant direct effect between small numbers and integration (hypothesis 2). Hypothesis 3 is confirmed, so environmental uncertainty is positively related to vertical integration in the presence of a non-trivial degree of asset specificity. We do not find support for hypothesis 4 , referring to the positive effect of measurement problems on vertical integration.

Hypothesis 5 is that larger firms are less likely to internalize their input needs due to diseconomies of scale. As expected, the result for this variable indicates that size negatively affects a firm's vertical integration decision.

The findings in this paper do not support all of the hypotheses suggested on the basis of the resource and capability-based approach. According to hypothesis 6, marketingintensive firms are more likely to choose integration for their transactions. We find weak evidence for this hypothesis (the coefficient associated with innovation intensity has $\mathrm{p}$-value $=0.052$ ). With respect to innovation-intensive firms, our evidence fails to support hypothesis 7 . However, our results provide stronger support for hypothesis 8 , which implies that experience is significantly associated with vertical integration.

In terms of the hypotheses linked to the strategic management literature, hypothesis 9 predicted that a higher product quality mix would push transactions away from the market and into vertical integration. In particular, it was argued that the likelihood of market failure was most severe in exchanges that exhibited high differentiation based on product quality. Our results from model IV provide partial support for this hypothesis.

As a robustness check ${ }^{4}$, ordered logit models that included eight choices for the dependent variable (Parmigiani 2007) were run, using all variables included in model IV, to replicate the tobit models. The results were quite similar, corroborating the robustness of the model.

Our results provide evidence that a combination of strategy, transactional and firmspecific factors appears to offer a useful explanation of the vertical integration decision of firms in the wine-industry.

The incremental benefit from including each set of factors in the analysis can be evaluated through statistical significance. In this way, we can see that transactional attributes are highly effective in explaining vertical integration decisions (Nagelkerke's $\mathrm{R}^{2}=0.374$ ). Transactional attributes contribute to the vertical integration decision in different ways. Consistent with transaction cost analysis is the finding that the vertical integration decision is stronger as asset specificity increases: firms integrate to avoid lock-in problems that may arise from large sunk investments. We find that upstream physical asset specificity and dedicated asset specificity have the appropriate sign and

\footnotetext{
${ }^{4}$ Results are available upon request.
} 
are statistically significant. However, downstream physical asset specificity has a much less significant impact on the decision to integrate these transactions. This result is consistent with the fact that increasingly a winery's profitability is not limited to winemaking. Indeed, many regional winemakers diversify their winery activities in order to develop additional income streams through a commitment to wine and cultural tourism (Lumbreras 2004).

The results fail, however, to support the small-numbers hypothesis, which is a less central prediction of the transaction cost model. This finding contradicts previous empirical work (e.g., Levy 1985; Caves, Bradburd 1988). However, this non-significant result could have at least two explanations. One possible explanation is that in the DOC Rioja wine industry there are enough suppliers available to make small-numbers bargaining problems a minor consideration. Another possible explanation is that our measure of existing suppliers is a noisy measure of the real supplier availability (Bigelow, Argyres 2007). Bhuyan (2005) also found an insignificant effect for small numbers.

We also find support for Williamson's (1985) proposition that environmental uncertainty, in presence of a non-trivial degree of specificity, raises transaction costs appreciably. Thus, hypothesis 3 is supported. We also performed these analyses for the case where the dummy variable $\lambda=1$ when the values of all items of specificity is above 2 , and 0 otherwise. The results of the empirical analyses were not substantially changed by altering the interaction variable in this way.

The results provide weaker support for hypothesis 4, that increased measurement problems in the transaction leads to an increased use of vertical integration. This result apparently contradicts the findings of other empirical papers. However, unique features of the industry might explain this divergence. European wine growers and wine producers are based in small villages where people know about each another reasonably well through an efficient mouth-to-mouth communication network. Hence, the contractual parties have information about each other prior to entering into a relationship. Some of these parties are family members and others are introduced by a neighbour or relative. In such a circumstance, reputation certainly matters and it diminishes the possible effect of internal uncertainty, because those behaving badly would soon become known in the industry (Fernández 2008).

Consistent with hypothesis 5 , the size of the winery is negatively related to vertical integration. According to the transaction cost approach, the incentive for vertical integration is negated by strong diseconomies of scale, so diseconomies of scale could be a factor limiting the extent of vertical integration (Williamson 1974). Applying this argument to viticulture, the diseconomies of scale are generated by the distance between the vineyard and the winery. We know that a key aspect in improving wine quality is to control the entire production process, from vineyard planting to the finished product. When a winery needs large quantities of grapes, its supplier vineyards cannot all be next to the winery. Hence, in large wineries with the integrated production of grapes, managers would need to spend a lot of time visiting their vineyards.

In order to examine whether the internal pool of capabilities really adds explanatory power to our model, Nagelkerke's $\mathrm{R}^{2}$ was compared for model III and model II. The 
observed increase in Nagelkerke's $\mathrm{R}^{2}$ was 0.085 and this demonstrates that firm-specific capabilities also increase the explanatory power of the model. In general, the availability or the creation of capabilities in the firm definitely increases the degree of backwards vertical integration. However, research and development expenditure is insignificant, so there is a lack of support for hypothesis 7 . In keeping with hypothesis 4 , the discrepancies could be due to differences in the specific characteristics of the industry, since innovation efforts in wineries appear not to affect the grape crop.

In contrast, hypothesis 8 addresses the effect of experience on vertical integration. This hypothesis is tested using the coefficient of the term experience. This coefficient is positive and highly significant, which corroborates the hypothesis proposed.

We have obtained support for the hypothetical relation between a firm's focus on high value added products and the degree of vertical integration. This result is consistent with the classical Edmonds (1923) proposition suggesting a high quality or willingness-topay effect associated with vertical integration. In many manufacturing industries such a proposition has become weaker as advances in standardization and information technologies has allowed stronger de facto integration with external suppliers. However, the proposition retains its validity in the food industry where such advances have been less evident.

Finally, the results of this study are generally consistent with the existing empirical literature on the subject. Previous studies have suggested that entering new stages in the value chain is conditioned not only by transaction costs but also by production cost differences (Argyres 1996; Leiblein, Miller 2003). In keeping with these studies, we found that firms integrate to reduce transaction costs and to protect strategic resources and capabilities, among other motives. Similar to Díez-Vial (2007), we also found that transactional attributes are more relevant than capabilities in explaining firms' boundaries. While this result appears to contradict other empirical papers, differences in the measures might explain this divergence (Leiblein, Miller 2003).

\section{Conclusions}

Understanding the factors that determine which type of transactions are undertaken through markets and which are undertaken inside firms has been an important theoretical and empirical issue in the economics and management literature. Although there is already considerable research on the determinants of vertical integration, this paper develops and tests a model of the vertical integration choice that contributes to the literature by analyzing strategies, transactions and firms' attributes. The main results indicate that transaction costs, firm-level capabilities and differentiation strategies independently and significantly influence a firm's vertical boundary choices.

In addition to the transaction cost approach and the capability-based view, the strategy management literature appears to offer a useful explanation of the use of vertical integration. The influence of the product differentiation strategy on the vertical integration decision is an important distinction in our model. Our study suggests that firms that want highly differentiated products have a greater likelihood of internalizing production. 
The analysis presented here leaves some interesting questions about the governance mode choice unanswered. Our study focuses on vertical integration decisions in the wine industry. Thus, our conclusions and inferences from the results may be limited to this setting, rather than explaining the vertical integration choice in other industries. However, we believe that many of the factors found in the current study to be associated with firm boundaries also apply in other settings, particularly in differentiated-product industries with fairly non-standardized supplies.

Another potentially complementary perspective for exploring the determinants of the vertical integration decision could be the economics of property rights. With this approach, property rights to resource attributes consist of the rights to use, consume, obtain income from, and alienate these attributes. As a consequence, property rights are important in viticulture because a vineyard owner's ability to create, appropriate, and sustain value from it partly depends on the property rights that he or she holds and how well they are protected.

A cross-sectional research approach was chosen for this paper in order to provide comparability with existing research on the vertical boundaries of the firm. The stability of the relationships between the attributes of a given transaction, relevant capabilities, and governance decisions over time remains an untested area worthy of attention. In the wine industry, it would have been helpful to have data on the wineries' experiences in previous growers-wineries relationships. With this information, we could analyze how this factor reduces negotiation costs and allows wineries to develop capabilities of use when choosing and maintaining new relationships.

While this study emphasizes the insights from the different views on vertical integration found in the management and economics literature, interactions between the different approaches are not considered. Given that we found some correlation between explanatory factors, it would be interesting in future research to test how these influence each other.

\section{Acknowledgements}

We gratefully acknowledge funding from MICINN-FEDER through research project ECO2009-09623 and from DGA-FSE through CREVALOR research group.

\section{References}

Anderson, E. 1985. The salesperson as outside agent or employee: a transaction cost analysis, Marketing Science 4: 234-254. http://dx.doi.org/10.1287/mksc.4.3.234

Anderson, E.; Schmittlein, D. 1984. Integration of the sales force: an empirical examination, Rand Journal of Economics 15: 385-395. http://dx.doi.org/10.2307/2555446

Argyres, N. 1996. Evidence on the role of firm capabilities in vertical integration decisions, Strategic Management Journal 17: 129-150.

http://dx.doi.org/10.1002/(SICI)1097-0266(199602)17:2<129::AID-SMJ798>3.0.CO;2-H

Barney, J. 1986. Strategic factor markets: expectations, luck, and business strategy, Management Science 32: 1231-1241. http://dx.doi.org/10.1287/mnsc.32.10.1231

Barney, J. 1999. How a firm's capabilities affect boundary decisions, Sloan Management Review Spring: 137-145. 
Barney, J. 2002. Gaining and sustaining competitive advantage. New Jersey: Pearson Education. Bhuyan, S. 2005. An empirical evaluation of factors determining vertical integration in U.S. food manufacturing industries, Agribusiness 21: 429-445. http://dx.doi.org/10.1002/agr.20056

Bigelow, L.; Argyres, N. 2007. Transaction costs, industry experience and make-or-buy decisions in the population of early U.S: auto firms, Journal of Economic Behavior \& Organization 66: 791-807. http://dx.doi.org/10.1016/j.jebo.2006.01.010

Caves, R.; Bradburd, R. 1988. The empirical determinants of vertical integration, Journal of Economic Behavior and Organization 9: 265-279. http://dx.doi.org/10.1016/0167-2681(88)90037-6

Coase, R. 1937. The nature of the firm, Economica 4: 386-405.

http://dx.doi.org/10.1111/j.1468-0335.1937.tb00002.x

Coles, J.; Hesterly, W. 1998. The impact of firm-specific assets and the interaction of uncertainty: an examination of make or buy decisions in public and private hospitals,. Journal of Economic Behavior \& Organization 36: 383-409. http://dx.doi.org/10.1016/S0167-2681(98)00102-4

Díez-Vial, I. 2007. Explaining vertical integration strategies: market power, transactional attributes and capabilities, Journal of Management Studies 44: 1017-1040.

http://dx.doi.org/10.1111/j.1467-6486.2007.00693.x

Edmonds, C.C. 1923. Tendencies in the automobile industry, The American Economic Review 13: 422-441.

Fernández, M. 2008. Why use contracts in viticulture?. The Journal of Wine Research 19(2): 81-93. http://dx.doi.org/10.1080/09571260802622126

Fowler, F. J. 1995. Improving survey questions: design and evaluation. Thousand Oaks: Sage.

Frank, S.; Henderson, D. 1992. Transaction costs as determinants of vertical coordination in the U.S. food industries, American Journal of Agricultural Economics 74: 941-950.

http://dx.doi.org/10.2307/1243192

Gatignon, H.; Anderson, E. 1988. The multinational corporation's degree of control over foreign subsidiaries: an empirical test of a transaction cost explanation, Journal of Law, Economics, and Organization 4: 305-336.

Hill, C. W. L.; Jones, G. R. 2008. Strategic management: an integrated approach. $8^{\text {th }}$ ed. Boston, MA: Houghon Mifflin.

John, G.; Weitz, B. A. 1988. Forward integration into distribution: an empirical test of transaction cost analysis, Journal of Law, Economics and Organization 4: 121-139.

Klein, B.; Crawford, R.; Alchian. A. 1978. Vertical integration, appropriable rents, and the competitive contracting process, Journal of Law and Economics XXI: 297-326.

http://dx.doi.org/10.1086/466922

Kumpe, T.; Bolwijn, P. T. 1988. Manufacturing: the new case for vertical integration, Harvard Business Review 66(2): 75-81.

Leiblein, M.; Reuer, M.; Dalsace, F. 2002. Do make or buy decisions matter? The influence of organizational governance on technological performance, Strategic Management Journal 23: 817-833. http://dx.doi.org/10.1002/smj.259

Leiblein, M. J.; Miller, D. J. 2003. An empirical examination of transaction and firm level influences on the vertical boundaries of the firm, Strategic Management Journal 24: 839-859.

http://dx.doi.org/10.1002/smj.340

Levy, D. 1985. The transaction cost approach to vertical integration: an empirical examination, The Review of Economics and Statistics 67: 438-445. http://dx.doi.org/10.2307/1925972

Lumbreras, J. 2004. Enoturismo por la Rioja Jacobea, La Prensa del Rioja 150: 16-21.

Martin, S. 1986. Causes and effects of vertical integration, Applied Economics 18: 737-755. http://dx.doi.org/10.1080/00036848600000089 
McVey, J. S. 1972. The industrial diversification of multi-establishment manufacturing firms: a developmental study, Canadian Statistical Review 47: 112-117.

Nelson, R. R.; Winter, S. G. 1982. An evolutionary theory of economic change. Cambridge: Belknap Press.

Parmigiani, A. 2007. Why do firms both make and buy? An investigation of concurrent sourcing, Strategic Management Journal 28: 285-311. http://dx.doi.org/10.1002/smj.580

Poppo, L.; Zenger, T. 1998. Testing alternative theories of the firm: transaction cost, knowledgebased, and measurement explanations for make-or-buy decisions in information services, Strategic Management Journal 19: 853-877.

http://dx.doi.org/10.1002/(SICI)1097-0266(199809)19:9<853::AID-SMJ977>3.0.CO;2-B

Porter, M. W. 1980. Competitive strategy. New York, NY: Publishing, Co.

Robins, J. A.; Wieserman, M. F. 1995. A resource-based approach to the multi-business firm: empirical analysis of portfolio interrelationships and corporate financial performance, Strategic Management Journal 16: 277-299. http://dx.doi.org/10.1002/smj.4250160403

Russo, M. 1992. Power plays: regulation, diversification, and backward integration in the electric utility industry, Strategic Management Journal 13: 13-27.

http://dx.doi.org/10.1002/smj.4250130103

Scherer, F. M.; Ross, D. 1990. Industrial market structure and economic performance. Boston, MA: Houghton Mifflin.

Wernerfelt, B.; Montgomery, C. A. 1988. Tobin's q and the importance of focus in firm performance, American Economic Review 78: 246-250.

Williamson, O. E. 1974. The economics of antitrust: transaction cost considerations, University of Pennsylvania Law Review 122: 1439-1496. http://dx.doi.org/10.2307/3311505

Williamson, O. E. 1975. Markets and hierarchies. New York: Free Press.

Williamson, O. E. 1979. Transaction-cost economics: the governance of contractual relations, Journal of Law and Economics 22: 233-262. http://dx.doi.org/10.1086/466942

Williamson, O. E. 1981. The economics of organization: the transaction cost approach, American Journal of Sociology 87: 548-577. http://dx.doi.org/10.1086/227496

Williamson, O. E. 1985. The economic institutions of capitalism. New York: Free Press.

Williamson, O. E.1991. Comparative economic organization: the analysis of discrete structural alternatives, Administrative Science Quarterly 36: 269-296. http://dx.doi.org/10.2307/2393356

Marta FERNÁNDEZ-OLMOS (PhD, Extraordinary Award of doctoral thesis from University of Zaragoza) is Associate Professor of Business Organization at the University of Zaragoza. She belongs to the Crevalor Research Group of the University of Zaragoza. Her research interests are vertical relations and internationalization of small and medium enterprises.

Natalia DEJO-ORICAIN (PhD, Universidad de Zaragoza) is Assistant Professor of Business Organization at the University of Zaragoza (Spain). She belongs to the Crevalor Research Group. Her research interests include product differentiation strategy and internationalization of small firms.

Jorge ROSELL-MARTíNEZ, PhD, is Professor of business economics and Vice Dean of the Defense Universitary Center, in the General Military Academy of Spain. He belongs to the Crevalor Research Group. His research interest is the economic analysis of the firm, in fields like vertical integration, spillovers, and economic measurement of profit and capital. 